\title{
Continuous Development and Operation of a Regional Digital Archive System as Project-Based Learning
}

\author{
Taku Okuno, Toshio Kawashima *
}

\begin{abstract}
Future University Hakodate, in cooperation with Hakodate City Central Library, has developed a digital archive system. To maintain the archive within a limited budget and allow it to be used for research and education, students participated in the development and the operation of the archive. Activities related to the digital archives are particularly valuable for project-based learning. Skills that can be obtained through such activities include system development and project management. The former includes programming and system integration for business applications. The latter includes team management and stakeholder management.
\end{abstract}

Keywords: system development, project management, project-based learning, digital archives

\section{Introduction}

Recently, digital archives of regional historical records have been widely developed. In Hakodate City, Future University Hakodate, in cooperation with Hakodate City Central Library, has been developing and operating a regional digital archive system. In a cooperative effort, both organizations are continuously digitizing vast numbers of historical records, archiving them, and improving the functions and usability of the system.

To maintain the archives within a limited budget and allow the archives to be used for research and education, students have participated in the development and operation of the archives. The educational aspect is particularly important because the university offers Project Based Learning (PBL) courses as the centerpiece of its curriculum. Among the various PBL subjects, system development is very important at the university.

In this article, we focus on the educational aspect of the activities. We describe the development and operation of the regional digital archive system as it relates to PBL. We also discuss the skills students gain through activities related to the digital archives. We first survey related work on PBL activities related to information system development. Then we present an overview of Hakodate City's regional digital archives. This includes history, display functions, access statistics, development, and operation. These descriptions help to understand in detail the real-world problem students are working on. After that, we describe the development and operation from the aspect of project management. This

* Future University Hakodate, Hakodate, Japan 
includes project team, technical information sharing, ticket driven development, and communication. Then the skills to be obtained through activities include system development and project management are discussed. Finally, the effectiveness of participating in the development and operation of the digital archive system as it relates to ICT education is discussed.

\section{Related Work}

This section discusses PBL activities related to information system development.

Gackowski has reported case and real-life problem-based learning associated with computer information system projects [1]. He noted that realistic PBL inspires greater motivation and provides observable satisfaction derived from a demonstrable and tangible outcome. In Gackowski's study, PBL takes place in an academic environment over a single semester; however, given the limited duration, it does not cover the entire life cycle of a system. He also explains that regular operations and system maintenance continue until the system is discontinued or replaced by a subsequent version.

Vat has reported how a team of students could be empowered by developing an information system through self-directed learning and team collaboration [2]. Vat states that the analytical process involves understanding real-world problems and user needs and proposing solutions to meet those needs. In his study, each PBL team is assigned a dual role, i.e., client and developer. Each team, acting as the developer, must complete an interactive system design and prototype for another team acting as the client.

Tozawa has reported the activities of a graduate PBL course at an industrial technology university [3]. He noted that the external evaluators commented on the appropriateness of the project's subject. Tozawa explains that they recognize the importance of using realworld on-going problems rather than canned problems. However, this is difficult because most students at this university work during the day; therefore, it is difficult to find the time to communicate with stakeholders effectively.

In terms of PBL content, development and operation of the regional digital archive system differ from the PBL activities described above. In our case, we are dealing with a real-world problem. The developed system has been operated by students in association with the client. The student team receives continuous feedback from the client and end users. These activities continue over semesters and years by alternating generations of students. Thus, the PBL covers most of the system's life cycle. Details of the problem, the developed system, and the PBL features will be explained in the following sections.

\section{Overview of Hakodate City Central Library Digital Archives}

\subsection{History}

The Hakodate City Library has collected an enormous number of historical records, particularly records relating to the northern area of Japan. In fact, the collection has been called the treasury of historical records of northern Japan. However, in terms of preserving the collection, secondary sources have been inadequate. The Hakodate City Central Library has been digitizing these historical records since 2003 in preparation for its relocation from an aging building to a newly constructed building with LAN facilities. 
The historical records have been digitized in order of priority according to type. Highest priority has been given to maps and documents because they are deteriorating due to age. These items have been digitized by the library. Photographs and picture postcards have been digitized by the university because they are useful for research. Posters, scrolls, and framed pictures have also been digitized. These items are difficult for the library to handle because their shapes differ from conventional books. Furthermore, this collection includes precious works and allowing library users to access the originals requires extra care. Thus, digital archival exhibition of such precious works is most appropriate.

Future University Hakodate began developing a digital archive content management system (CMS) in 2007. The CMS manages and displays the digitized collection. In 2008, the Hakodate City Central Library Digital Archives became operational [4][5]. In 2010, the Digital Archives Research Center was established at Future University Hakodate for continuous development and operation of the digital archive system.

\subsection{Display Functions}

A thumbnail view of the digital archives is shown in Figure 1. By clicking a tab (indices) on the left side of the search box in the header area of the window, a thumbnail view of the selected category will be loaded. At present, six categories, i.e., documents and maps, picture postcards, posters, scrolls and frames, photographs, and ukiyo-e prints are available. A pair of buttons in the upper left of the thumbnail area toggles the view between a thumbnail matrix and a catalog list with thumbnails. Figure 1 shows the result of keyword search with the string "byobu." Byobu refers to a folding screen in Japanese.

By clicking a thumbnail in the thumbnail view, a detailed view of the corresponding record will appear. In this view, a large image and catalog data are displayed. The image is displayed using the Zoomify viewer, which allows a user to zoom in and out smoothly using a slider and pan across the image by dragging the image. Note that the Zoomify viewer will be described in greater detail in a subsequent section. Figure 2 is a detailed view of the record (thumbnail) that is located second from the left in the middle row in Figure 1. This is a high-resolution picture of a six-panel folding screen with a painted landscape of Fukuyama port at Matsumae. The center of the third panel from the left in Figure 2 at maximum magnification is shown in Figure 3. In this image, buildings and people performing various activities can be seen clearly. The lower part of the picture shows packages arriving by boat, heaped up on the beach, and carried by workers on their backs. High-resolution images of historical records combined with zoom and pan functions and the keyword search function can help researchers investigate historical records efficiently.

Initially, the digital archives system was intended to be used with a PC. However, since 2014, along with the change of the library reference terminals for the archives from PCs to tablet devices, the system has been adapted to support such devices. Since the upgrade of the system in September 2014, it has supported limited access to particular records by the library reference terminals.

\subsection{Access Statistics}

As of February 2016, the total number of records in the system is 13,458 , which includes 6,242 records to which access is limited by the library reference terminals. The total number of images is 192,919. The number of records and images by category is shown in Table 1 . Table 1 shows that, compared to the number of records, the number of images is extremely 


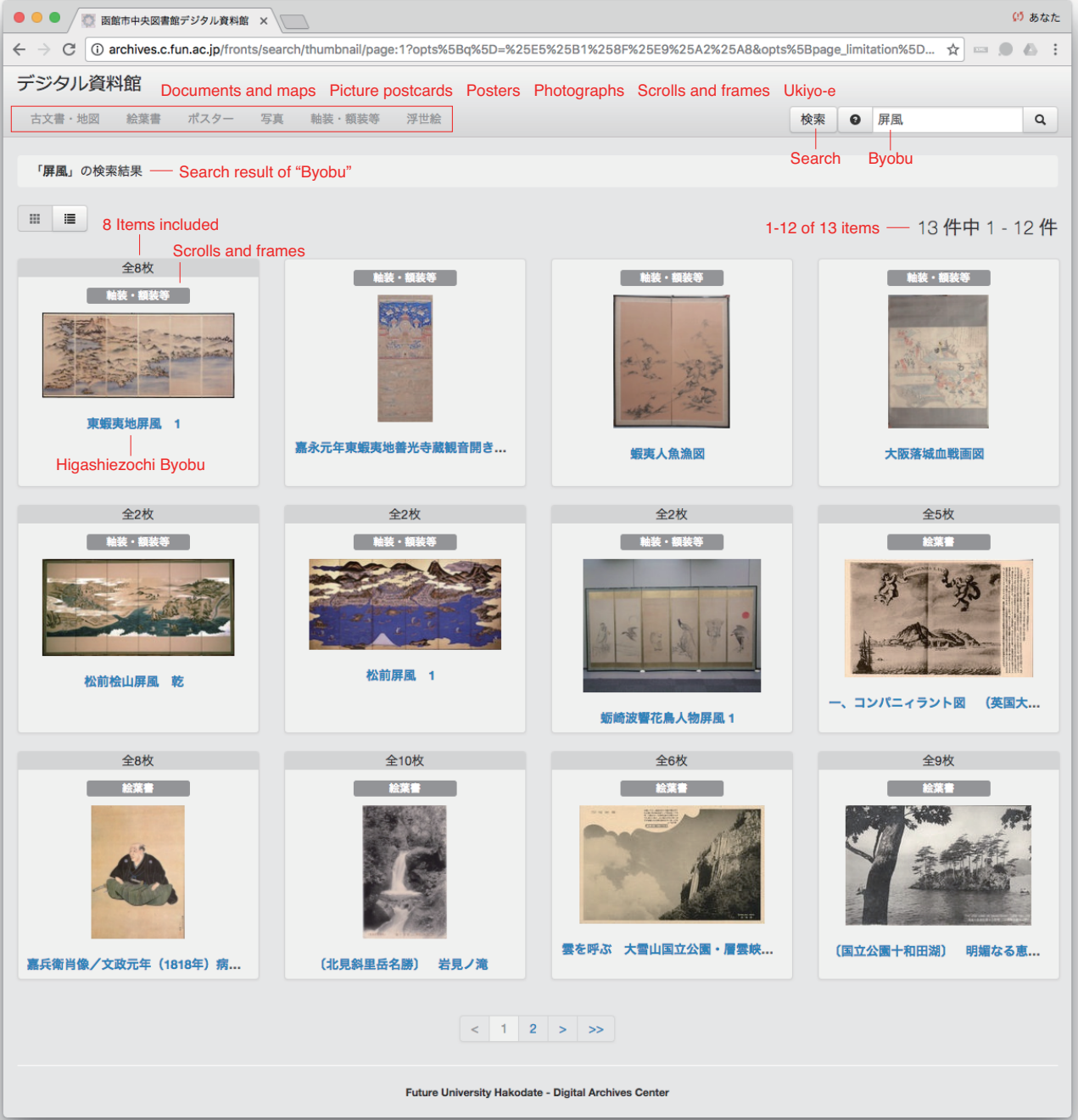

Figure 1: Digital archive list view (thumbnail view of a search result for the string "byobu") 


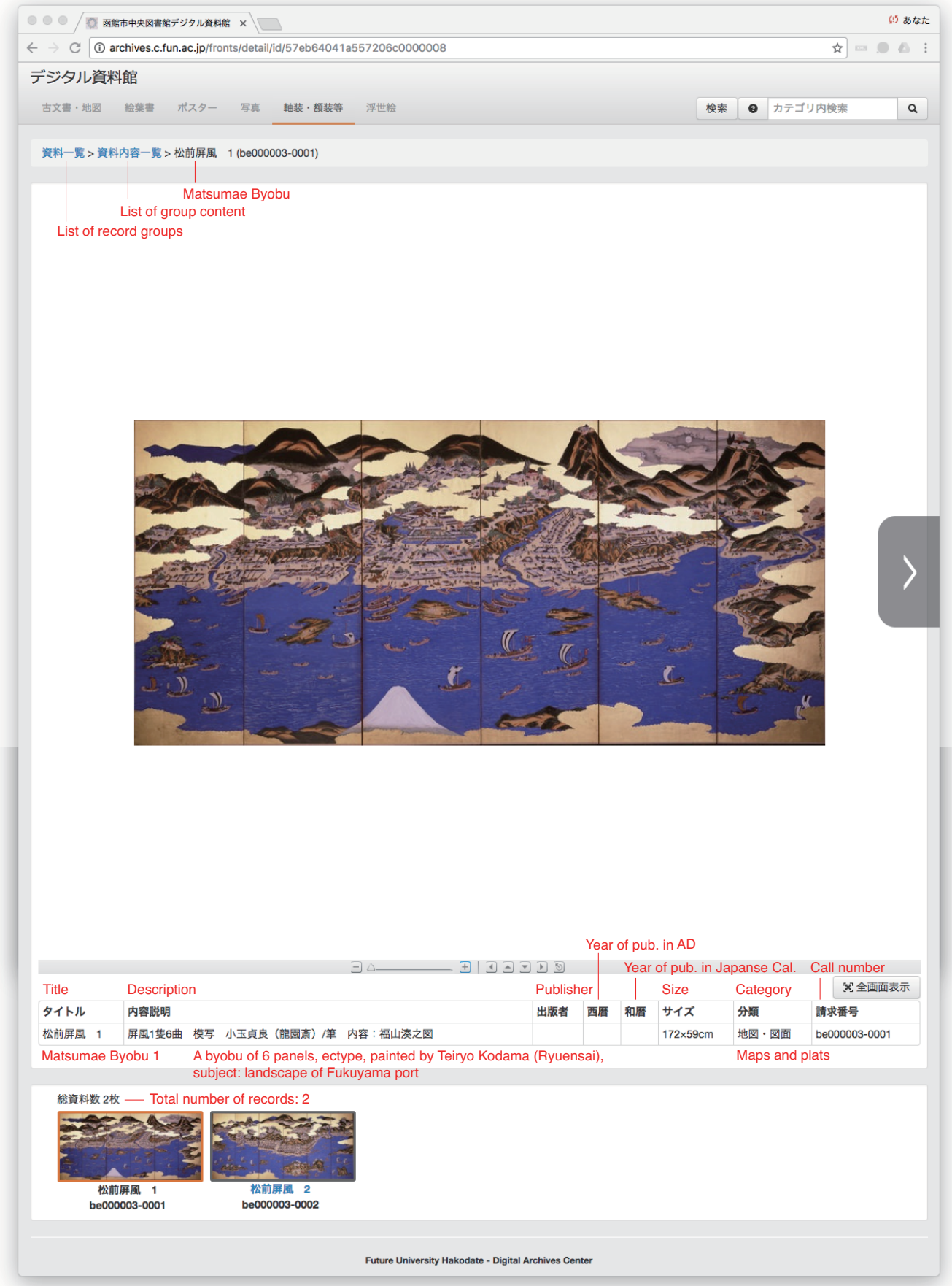

Figure 2: Detailed view of a digital archive (maximum zoom out) 


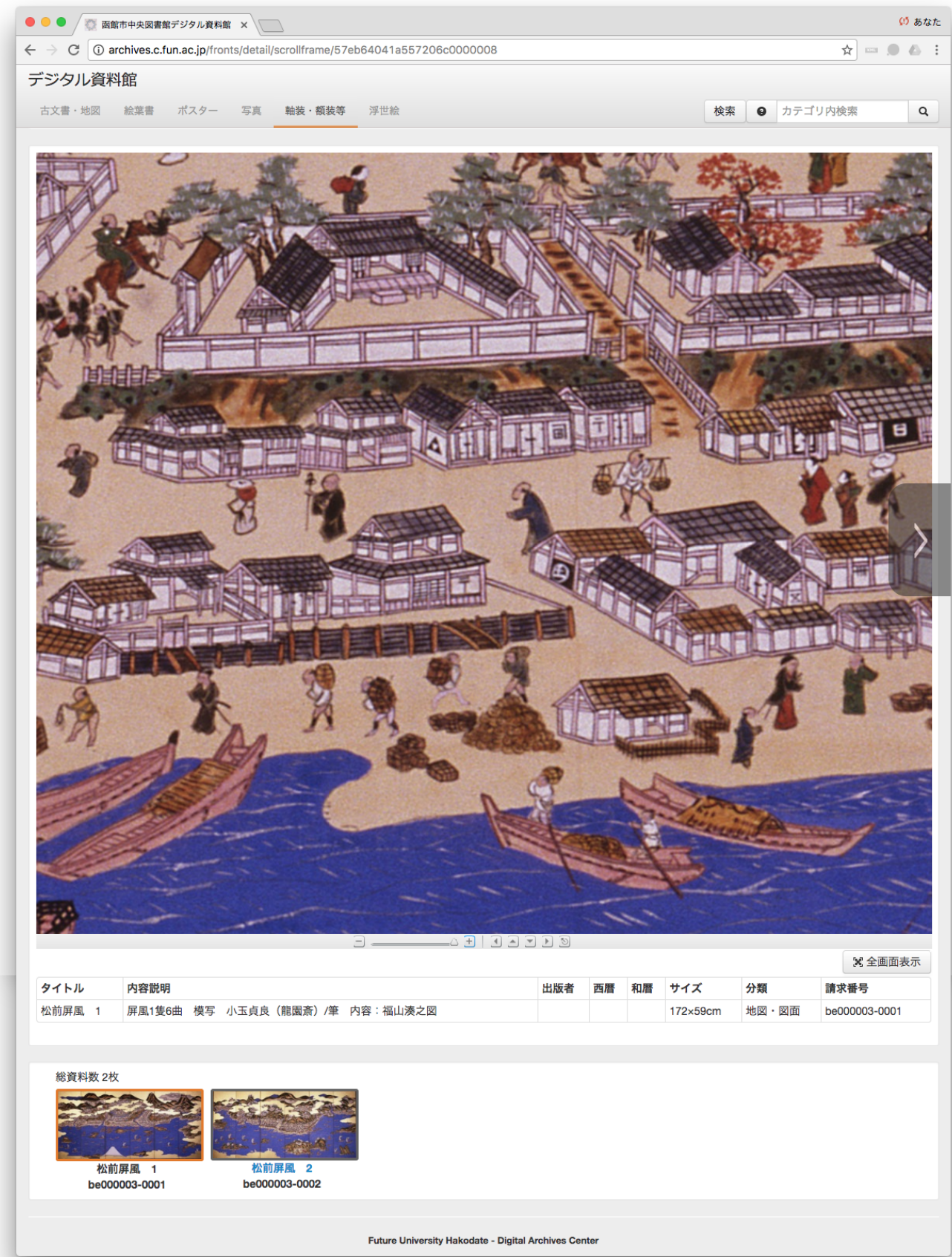

Figure 3: Detailed view of a digital archive (maximum zoom in) 
large. This is because many of the documents have hundreds of pages, and each page is archived independently as an image.

In FY2013, approximately 100 records were added each month. In the first half of FY2014, approximately 300 records, primarily of limited access, were added. From the latter half of FY2014 to the end of FY2015, approximately 600 full access records and approximately 6,200 limited access records were added.

The digital archive access statistics from FY2013 to FY2015 are shown in Table 2. The number of page views for the entire site in FY2015 was 669,340, and the number of users was 26,676 . The sessions, users, and page views for the entire site have increased by approximately $60 \%$ since FY2013.

Sessions by domestic region from FY2013 to FY2015 are shown in Table 3. Approximately half of the sessions were accessed by users outside of Hokkaido where Hakodate is located. The number of sessions from each region, except Hokkaido, appears to reflect regional population. The ratio of accesses from outside to inside Hokkaido has been increasing annually. This indicates that awareness of the archives has gradually been spreading throughout the country.

Sessions by world region from FY2013 to FY2015 are shown in Table 4. The ratio of accesses from overseas to domestic regions has been increasing gradually year by year. In fact, in the past two years, the number of overseas accesses has increased by 2.5 times.

Table 1: Historical records by category as of Oct. 2016

\begin{tabular}{lrrrrrr}
\hline \multirow{2}{*}{$\begin{array}{c}\text { Categories of } \\
\text { historical records }\end{array}$} & \multicolumn{2}{c}{ Number of records } & & \multicolumn{2}{c}{ Number of images } \\
\cline { 2 - 3 } \cline { 6 - 7 } & access & $\begin{array}{c}\text { Full + limited } \\
\text { access }\end{array}$ & & Full & access & $\begin{array}{c}\text { Full + limited } \\
\text { access }\end{array}$ \\
\hline \hline Documents and maps & 1,009 & 2,487 & & 76,790 & 164,498 \\
Picture postcards & 3,816 & 4,207 & & 15,865 & 17,579 \\
Posters & 1,602 & 2,867 & & 1,622 & 2,888 \\
Photographs & 339 & 5,754 & & 726 & 9,179 \\
Scrolls and frames & 208 & 617 & & 324 & 843 \\
Ukiyo-e prints & 137 & 139 & & 422 & 426 \\
\hline Total & 7,111 & 16,071 & & 95,749 & 195,413 \\
\hline
\end{tabular}

Table 2: Access statistics for the entire digital archive site by year

\begin{tabular}{lrrr}
\hline \multicolumn{1}{c}{ Statistics } & FY2013 & FY2014 & FY2015 \\
\hline \hline Sessions & 28,849 & 34,230 & 44,490 \\
Users & 17,016 & 20,028 & 26,676 \\
Page views & 417,477 & 509,622 & 669,340 \\
Page views/session & 14.47 & 14.89 & 15.04 \\
Average session time & $6^{\prime} 25^{\prime \prime}$ & $6^{\prime} 35^{\prime \prime}$ & $6^{\prime} 31^{\prime \prime}$ \\
\hline
\end{tabular}

\subsection{Development}

The basic requirements for the regional digital archive system are long-term continuous operation, maintenance, and functional enhancements at low cost. In addition, the system is expected to be useful for research in various domains, such as digital archives, regional 
Table 3: Sessions by domestic region and year

\begin{tabular}{lrr}
\hline \multicolumn{3}{c}{ FY2013 } \\
\hline \multicolumn{1}{c}{ Domestic region } & \multicolumn{2}{c}{ Sessions (\%) } \\
\hline \hline 1. Hokkaido & 13,908 & $(49.61)$ \\
2. Tokyo & 5,548 & $(19.79)$ \\
3. Kanagawa Pref. & 1,211 & $(4.32)$ \\
4. Osaka Pref. & 1,046 & $(3.73)$ \\
5. Saitama Pref. & 805 & $(2.87)$ \\
6. Chiba Pref. & 514 & $(1.83)$ \\
7. Aichi Pref. & 490 & $(1.75)$ \\
8. Miyagi Pref. & 412 & $(1.47)$ \\
9. Aomori Pref. & 328 & $(1.17)$ \\
10. Kyoto Pref. & 305 & $(1.09)$ \\
\hline Total ex. Hokkaido & 14,128 & $(50.39)$ \\
Total & 28,036 & $(100)$ \\
\hline
\end{tabular}

\begin{tabular}{lrr}
\hline \multicolumn{3}{c}{ FY2014 } \\
\hline \multicolumn{1}{c}{ Domestic region } & \multicolumn{2}{c}{ Sessions (\%) } \\
\hline \hline 1. Hokkaido & 15,276 & $(46.46)$ \\
2. Tokyo & 7,066 & $(21.49)$ \\
3. Kanagawa Pref. & 1,495 & $(4.55)$ \\
4. Osaka Pref. & 1,034 & $(3.15)$ \\
5. Chiba Pref. & 968 & $(2.94)$ \\
6. Saitama Pref. & 769 & $(2.34)$ \\
7. Aomori Pref. & 580 & $(1.76)$ \\
8. Aichi Pref. & 536 & $(1.63)$ \\
9. Miyagi Pref. & 480 & $(1.46)$ \\
10. Kyoto Pref. & 422 & $(1.28)$ \\
\hline Total ex. Hokkaido & 17,601 & $(53.54)$ \\
Total & 32,877 & $(100)$ \\
\hline
\end{tabular}

\begin{tabular}{lrr}
\hline \multicolumn{3}{c}{ FY2015 } \\
\hline \multicolumn{1}{c}{ Domestic region } & \multicolumn{2}{c}{ Sessions (\%) } \\
\hline \hline 1. Hokkaido & 18,603 & $(43.11)$ \\
2. Tokyo & 9,176 & $(21.26)$ \\
3. Kanagawa Pref. & 3,021 & $(7)$ \\
4. Osaka Pref. & 2,176 & $(5.04)$ \\
5. Aichi Pref. & 1,070 & $(2.48)$ \\
6. Saitama Pref. & 942 & $(2.18)$ \\
7. Chiba Pref. & 909 & $(2.11)$ \\
8. Fukuoka Pref. & 881 & $(2.04)$ \\
9. Kyoto Pref. & 586 & $(1.36)$ \\
10. Aomori Pref. & 527 & $(1.22)$ \\
\hline Total ex. Hokkaido & 24,548 & $(56.89)$ \\
Total & 43,151 & $(100)$ \\
\hline
\end{tabular}

Table 4: Sessions by world region and year

\begin{tabular}{lrr}
\hline \multicolumn{3}{c}{ FY2013 } \\
\hline \multicolumn{1}{c}{ World region } & \multicolumn{2}{c}{ Sessions (\%) } \\
\hline \hline 1. Japan & 28,036 & $(97.18)$ \\
2. France & 188 & $(0.65)$ \\
3. United States & 156 & $(0.54)$ \\
4. China & 129 & $(0.45)$ \\
5. Taiwan & 70 & $(0.24)$ \\
6. South Korea & 68 & $(0.24)$ \\
7. Russia & 50 & $(0.17)$ \\
8. Hong Kong & 26 & $(0.09)$ \\
9. United Kingdom & 18 & $(0.06)$ \\
10. Germany & 16 & $(0.06)$ \\
\hline Total ex. Japan & 813 & $(2.82)$ \\
Total & 28,849 & $(100)$ \\
\hline
\end{tabular}

\begin{tabular}{lrr}
\hline \multicolumn{3}{c}{ FY2014 } \\
\hline \multicolumn{1}{c}{ World region } & \multicolumn{1}{c}{ Sessions $(\%)$} \\
\hline \hline 1. Japan & 32,877 & $(96.05)$ \\
2. United States & 267 & $(0.78)$ \\
3. Russia & 200 & $(0.58)$ \\
4. China & 132 & $(0.39)$ \\
5. Taiwan & 113 & $(0.33)$ \\
6. South Korea & 96 & $(0.28)$ \\
7. (not set) & 93 & $(0.27)$ \\
8. France & 82 & $(0.24)$ \\
9. Hong Kong & 81 & $(0.24)$ \\
10. Germany & 38 & $(0.11)$ \\
\hline Total ex. Japan & 1,353 & $(3.95)$ \\
Total & 34,230 & $(100)$ \\
\hline
\end{tabular}

\begin{tabular}{lrr}
\hline \multicolumn{3}{c}{ FY2015 } \\
\hline \multicolumn{1}{c}{ World region } & \multicolumn{2}{c}{ Sessions (\%) } \\
\hline \hline 1. Japan & 43,151 & $(95.4)$ \\
2. United States & 550 & $(1.22)$ \\
3. Russia & 350 & $(0.77)$ \\
4. China & 241 & $(0.53)$ \\
5. Taiwan & 156 & $(0.34)$ \\
6. (not set) & 123 & $(0.27)$ \\
7. South Korea & 109 & $(0.24)$ \\
8. Germany & 55 & $(0.12)$ \\
9. Hong Kong & 54 & $(0.12)$ \\
10. United Kingdom & 51 & $(0.11)$ \\
\hline Total ex. Japan & 2,080 & $(4.6)$ \\
Total & 45,231 & $(100)$ \\
\hline
\end{tabular}


history, and software engineering. To fulfill such requirements, faculty at Future University Hakodate involved in digital archives research decided that the system would be developed by students majoring in information systems without the benefit of external developers.

The advantages of in-house development are as follows. First, experimental system improvements can be undertaken easily at low cost. Second, prototype systems developed for research into the archived historical records can be linked to the main system to facilitate use of the historical records and their metadata. To ensure long-term continuous development and operation of the digital archives, the members of the development team are selected from different years. Thus, annual turnover due to students graduating has less effect on team activities. Participation of students in the project is motivated by two factors. The first is the contribution to local society. One of the mission of the university is to contribute to local society. Students who contribute to local society earn good reputation from both local society and the university. The second is the opportunity to practice their skills. It is of great benefit to students to be involved in the development and operation of a system providing a real-world service.

The technologies and software tools used for development have been selected in terms of operational track records, availability of technical information, and future capability. Moreover, technologies and tools the students are familiar with have been given higher priority. The selected technologies and software tools for the current version of the digital archives system are as follows. CakePHP was selected as the Web application framework because it is easy to learn and the students are familiar with the PHP programming language [6]. This also makes it easier to integrate new students into the development of the system. MongoDB, which is a key-value store database, was selected for the database management system because the catalog items, i.e., metadata, of the historical records differ by type and new types will be added [7]. Zoomify, which is a commercial product, was adopted as the image viewer. Zoomify enables seamless and quick zooming of very high-resolution images in a manner similar to Google Maps [8].

The overall source code size of the digital archives system is 922,701 lines $(416,248 \mathrm{~K}$ bytes) at the end of February 2017. This includes the source code of CakePHP framework and nine software libraries for the user interface. The source code size of the framework is 198,372 lines ( $8,240 \mathrm{~K}$ bytes), and the total source code size of the libraries is 22,572 lines $(1,074 \mathrm{~K}$ bytes). Consequently, the size of source code written by students is 701,757 lines (406,934K bytes).

In parallel with operating and improving the current system, we are planning to rebuild the system to clean up messy source code caused by successive modifications and to replace legacy technologies with newer predominant technologies. This rebuilding will be indispensable within a few years for integrating new students familiar with newer technologies. The regular rebuilding of the system is included in the long-range plan of the digital archives.

\subsection{Operation}

Hakodate City Central Library uses an online public access catalog (OPAC) management system for its monograph collection as well as historical documents and maps. However, picture postcards, posters, scrolls, framed pictures, and photographs are difficult to manage with a system designed for monographs. Thus, a stand-alone database is used for these items. This database uses commercial general-purpose management software independent from the OPAC system. We refer to this database as the Non-OPAC DB. 


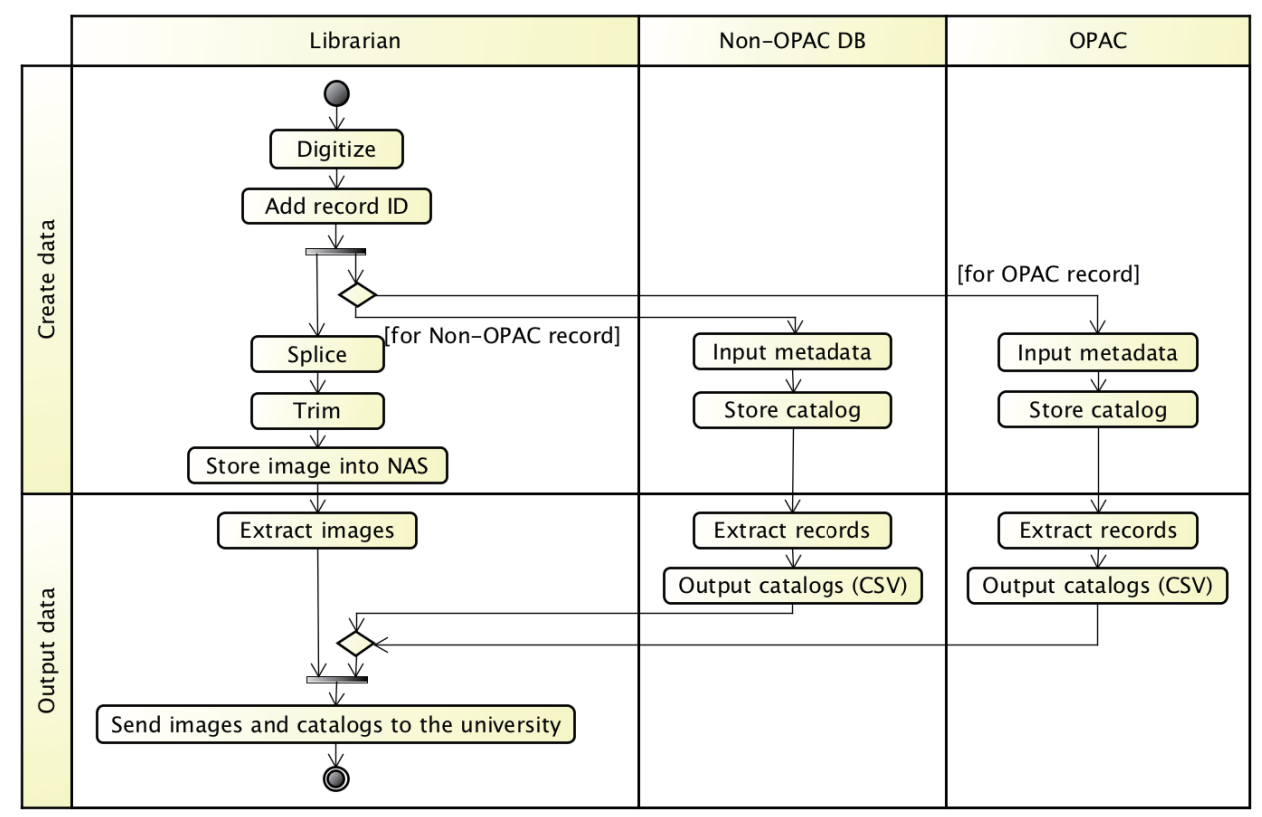

Figure 4: Workflow: creating and exporting images and generating catalog data

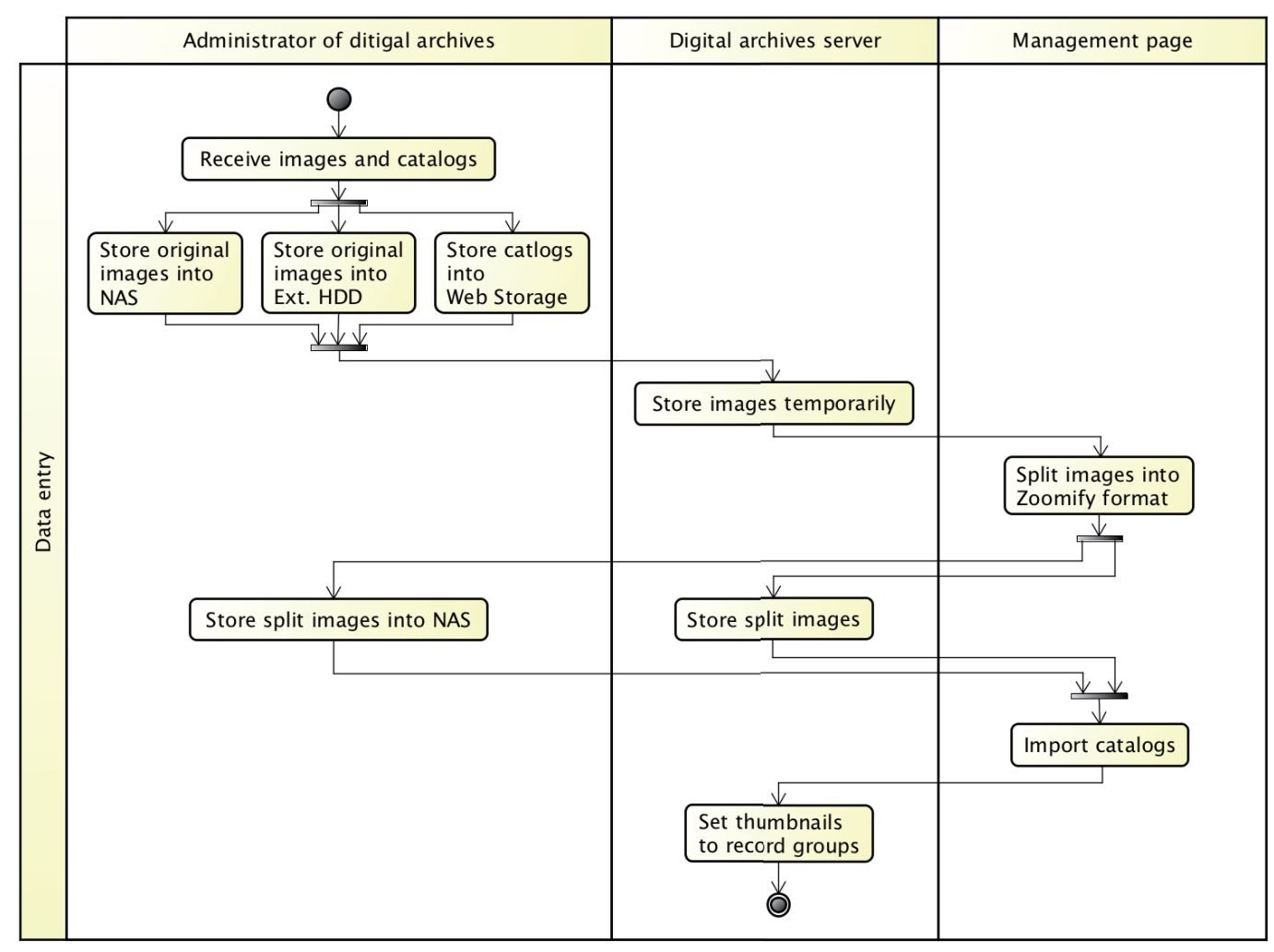

Figure 5: Workflow: entering images and catalogs to the digital archive system 
Digitizing, i.e., taking high-resolution photographs, and cataloging historical artifacts has been performed in the library. Inputting images and associated catalog entries has been performed at the university. The data creation, data output, and data entry workflow is illustrated using UML activity diagrams in Figures 4 and 5.

In the data creation process, historical records are digitized using a digital still camera and a unique record ID is assigned to each record, as shown in first row of the activity diagram in Figure 4. Then, the raw images are modified as follows. Partial images of a large record, e.g., long scrolls or folding screens, are spliced into a large image. Unnecessary image margins, including a chart for color correction, are removed. The corrected images are stored in network attached storage (NAS) connected to the LAN in the library. At the same time, catalog data are created for the images. An image is associated with the corresponding catalog by using the record ID as a key. Document and map catalog data are stored in the OPAC. The catalog data of the other categories are stored in the Non-OPAC DB.

In the data output process, the records to be displayed using the digital archive system are extracted from both the OPAC and the Non-OPAC DB, as shown in the bottom row of the activity diagram in Figure 4. The catalog data of the extracted records are exported in CSV format. Simultaneously, image files to be added to the digital archives are extracted from the NAS. Both the CVS catalog data and the corresponding image files are copied to a portable HDD that is sent to the university.

In the data entry process, as shown in Figure 5, the image files sent from the library are stored on both an NAS and an external HDD, and the catalog data are stored in Web storage. Then, the image files are uploaded to the digital archive system server via a remote terminal. In a Web browser, an image can be converted to Zoomify format, i.e., a set of multi-level split images. This is executed on the management page of the digital archive system. When the conversion process is complete, the split images are stored on the digital archive system server and the NAS. Then, after importing catalog data, each set of catalog data is associated with the corresponding set of image files. This is also executed on the management page. Finally, a script program is executed on the server to set the thumbnails to groups of records via a remote terminal.

Through the above processes, the records can be displayed using the digital archive system.

\section{Project Management}

\subsection{Project Team}

Relationships among the members of the student team and the stakeholders are shown in Figure 6. A student serves as team leader. The team leader drives both development and operations and is also regarded as the project manager because they perform most of the project management activities. Although they play both roles, in the following, they will be designated simply as the project leader (PL).

A faculty member supervises the student team. Supervision is conducted primarily through the PL. Essentially, development and operation of the digital archives are managed by the PL except when a tough decision is required. Similarly, the PL is in charge of communication with the library, except when tough negotiation is needed.

As stated in Section 3.4, the members of the development team consist of multi-year students. Figure 7 shows the continuance period for each student. A total of 19 students 


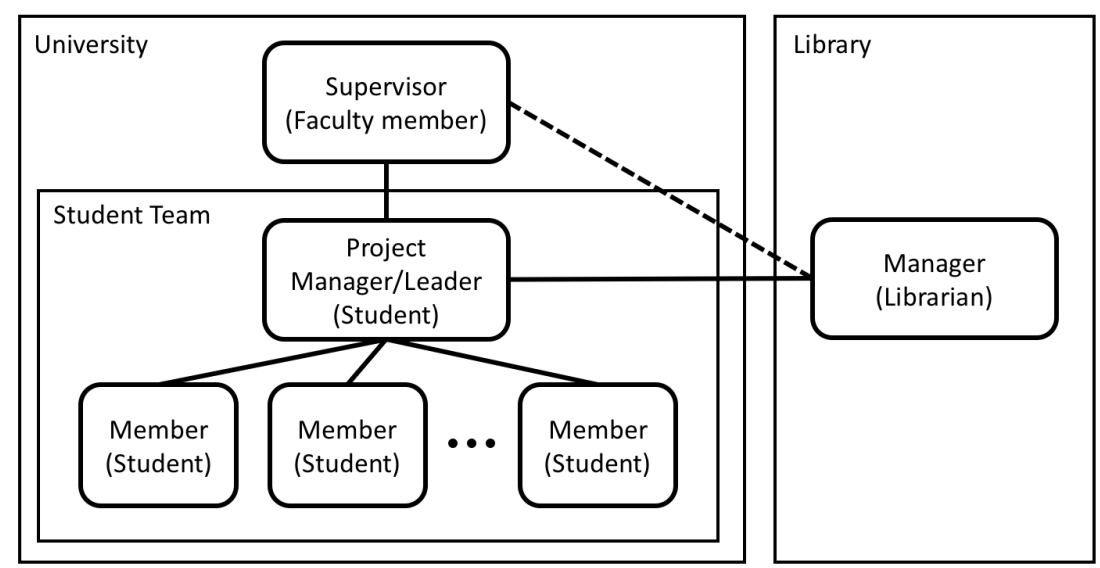

Figure 6: Relationship among project team members and stakeholders

(A-S) have been involved since 2011. The prefixes PL1, PL2, and PL3 indicate that those students have been PLs. The year each student entered the university is shown next to the students' labels on the vertical axis. The labels indicate the status of the students, i.e., graduate or undergraduate, at the end of their membership. For students currently on the team, the labels show their current status. Typically, the end of the continuance period corresponds to the year they graduated (at the end of March). At the time of graduation of a PL, the role of PL is taken over by the next PL. The chart shows that at least three members have stayed on the team during the transition from one academic year to the next. To ensure continuity, we have been trying to recruit undergraduates who plan to go on to graduate school at our university. This recruiting policy increases the possibility that a student will participate in the development of the system for a number of years.

\subsection{Technical Information Sharing}

Since 2011, integrated project management software, i.e., Redmine [9], has been implemented to facilitate ticket-driven development. Redmine is an open source Web application for project management and issue/bug tracking. It features wikis, forums, a calendar, Gantt charts, etc.

The Gantt charts visualize a project and its deadlines (milestones), in which each bar represents the schedule of a ticket. Redmine allows nested tickets, by which a task with subtasks can be managed effectively. This also means that the work breakdown structure (WBS) can be represented by an aggregation of tickets. In fact, the ticket hierarchy on the left side of the Gantt chart looks like a WBS.

In addition, Redmine integrates with various version control systems and includes a repository browser. This is important because all source code and other related files of the digital archive system have been managed using GitHub.

Figure 8 shows the overview page of the Redmine site for the digital archives project, which works as a portal to everything related to the project. This page includes a section of links to subprojects, a section of links to member profiles, a section for the project's policy for operating Redmine, a section of links to related documents, tools, and servers, and a section for the statistics of all tickets issued. 


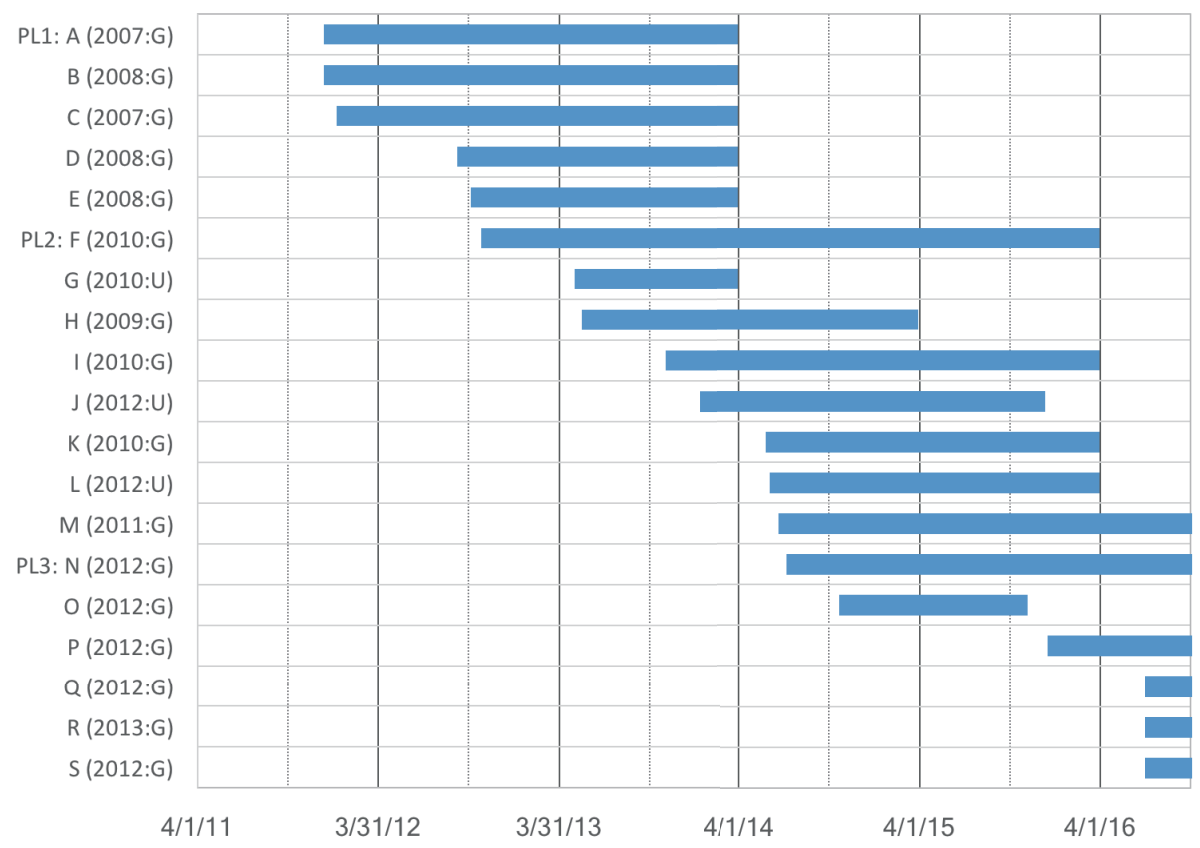

Figure 7: Continuance period of each team member

\subsection{Ticket Driven Development}

The members of the project, including the PL, are involved in the project as part-time workers who participate in the project in their spare time. Therefore, the working time of each member tends to be short, and the task backlog will remain for a long time. To manage tasks without mistakes in such a situation, ticket-driven development was introduced in 2011 [10]. Since then, no task in the project has been undertaken without issuing tickets.

Each ticket has certain properties, including ID, tracker, subject, description, status, priority, parent task, assigned to, start date, due date, and target version. The tracker denotes task categories, which include operation, development, bug, maintenance, and misc. Primarily, the PL has issued tickets, while other members have issued tickets if they find bugs or related tasks. For each issued ticket, a member is assigned by considering the priority and difficulty (time required) of the task in a weekly meeting, which will be described later.

Since 2011, 322 tickets have been issued, including 80 tickets for development, 68 for bugs, and 174 for operations. Operations include the maintenance of both system hardware and software, various communication with the librarians, and support for adding new records.

Table 5 shows statistics of the tickets assigned to team members. The left labels (A-S) indicate the team members, which correspond to the labels in Figure 7. Each number in the table shows the number of the tickets assigned to a member in each quarter of each year. The columns on the far right show the numbers of tickets according to category, development, bugs, and operations.

As shown in Table 5, more tickets have been assigned to the PLs compared to the other members. The number of tickets for operations is significant. The average number of tickets for operations assigned to the PLs is 33, while that for development and bugs is 10 . In other 


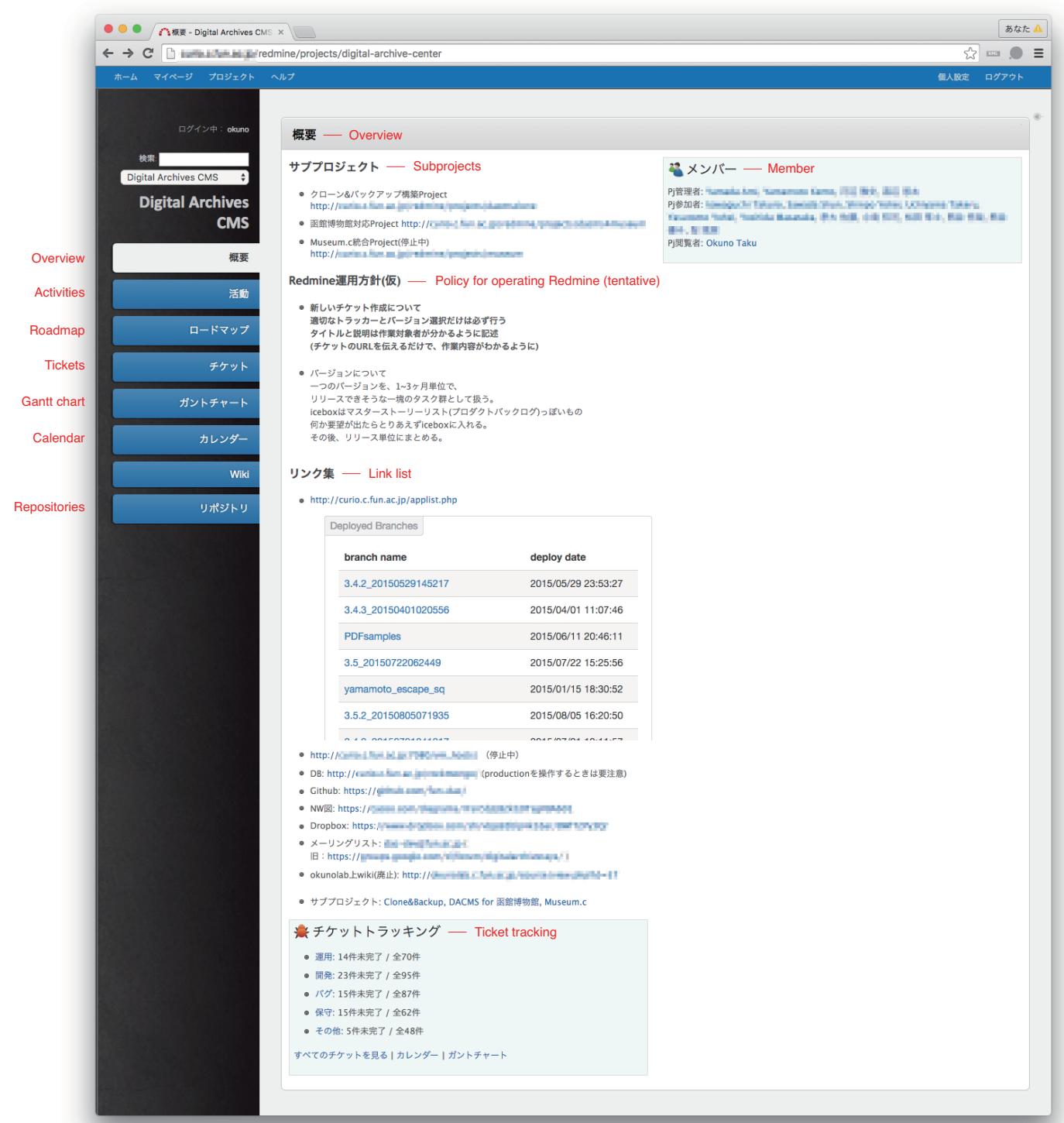

Figure 8: Redmine overview page for the digital archive project 
words, $77 \%$ of the tickets for the PLs are for operations. For other members, $47 \%$ are for operations. The difference is mainly caused by two factors. The first is that the tasks for communication with librarians are assigned to the PLs. Such tasks occur both regularly and unexpectedly. The second is that the tasks for adding new records and correcting existing records are assigned to the PLs. Although it is not an absolute necessity, it is convenient for operation because such tasks always involve communication with a librarian.

Note that the number of tickets is not always in proportion to the total workload for the tickets because workloads vary greatly from ticket to ticket. For example, the number of issued tickets from the end of 2015 to 2016 is smaller than those of the previous years. The reason for that is as follows. Until the end of 2015, most of the urgent bug fixes and improvements that are light tasks in general had been completed. As a result, since then, the project has started to address tasks that take much time. Accordingly, the number of tickets assigned has become smaller than before.

Table 5: Statistics of tickets assigned to team members

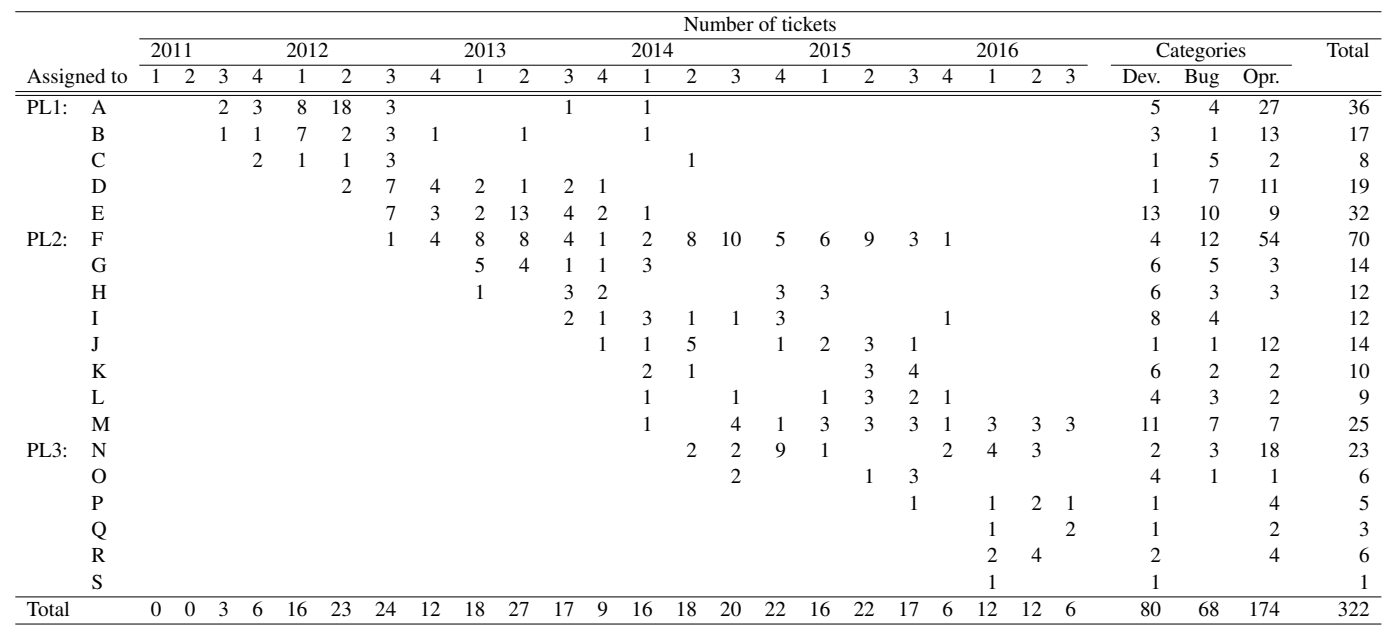

\subsection{Communication}

Communication among members of the project team occurs in person and online.

Face-to-face meetings are held weekly at the university, in which the PL has served as a facilitator. The meetings essentially consist of three parts: issue estimation, task assignment, and progress reports. First, the latest issues with the system are listed, including troubles, bugs found, and requests for improvement by the library. The members discuss solutions to the listed issues. Then, new tickets are created for the issues and are assigned to the members. Finally, the members report their current progress on open tickets.

At other times, members communicate using an online group chat system. For that, Skype was used until FY2014. Since FY2015, Slack has been used because it supports multiple channels in a team and Markdown format [11]. The minutes of the face-to-face meetings have been switched from Redmine to Slack [12] because the members prefer Markdown format.

For communication with library staff, e-mail is typically used. The PL serves as a contact person. To avoid misunderstandings caused by the usage of technical terms, e-mails 
regarding technical matters written by the students are reviewed by a supervisor.

\section{Skills}

The activities related to the digital archives are particularly valuable for PBL. The skills to be obtained through activities include system development and project management. The former includes programming and system integration for real business applications. The latter includes team management and stakeholder management. In this section, the skills to be obtained through activities related to the digital archives are discussed.

\subsection{System Development and System Integration}

As discussed in Section 3.4, the digital archive system has been developed completely at the university by a student team under the supervision of a faculty member.

Some members, including the PL, had participated in another extracurricular PBL course at the university [13]. One of the purposes of the course is mastering the practical skills required for developing information systems as a team. The skills obtained during the course include development of Web applications using application frameworks, setup of servers for operating the systems, and the use of various tools for software development, including version control systems.

The major difference between the digital archive system and the systems developed in the PBL course is that the former is operated as a real service. This means that a higher level of skills is required. Through the development and operation of the digital archive system, the students have learned much more than through the PBL course.

An example of the obtained skills is the ability to select technologies and software for stable system operation. This is a skill that should be possessed by system integrators. Essentially, choices are made in terms of track records relative to operation, the availability of technical information, and future capability (Section 3.4). To find the right technology and software, students should access a large amount of information, make difficult evaluations, and finally make decisions. A wrong decision will result in difficulties when developing the system. In the worst case, this can affect stable operation. This is the same for the design of the system.

\subsection{Project Management and Stakeholder Management}

As discussed in Section 4.1, the project is essentially managed by students. Similar to system development skills, some students have obtained project management skills through the PBL course. For example, information sharing using the project management portal, i.e., Redmine, ticket driven development, and version control using GitHub are learned in the PBL course.

Through the activities related to the digital archive system, the students have learned how to collaborate with the stakeholder, i.e., the library staff, without trouble. As described in Section 3.5, operation of the digital archives is complicated because different kinds of records must be handled by the system. The workflows shown in Figure 4 and Figure 5 are performed periodically. Accordingly, mistakes can be made at any point in the workflows. In fact, many troubles, including major and minor problems, have occurred. In this joint operation, the difficult point is how to narrow the scope of possibilities and track down causes. To solve such problems, the ability to look at the present situation from an objective 
standpoint is required, as well as deep understanding of the system and its operation. The team members have learned such skills through real troubleshooting.

Another skill the students have learned is expectation management. For successful development and operation of a system, appropriate management of stakeholder expectations is indispensable [14]. However, in many cases, this is difficult due to the differences in the backgrounds between developers and stakeholders. Perfect mutual understanding is extremely difficult to achieve. Students without social experience often misunderstand the stakeholder's underlying intent. This is why e-mails written by the students should be reviewed by a supervisor before being sent (Section 4.4). Similarly, the priorities of requests from the stakeholder tend to be misunderstood by students. In this case, the supervisor will point out the possibility of misunderstanding if necessary. Through supervision and responses from the stakeholder, the students have learned how to manage stakeholder expectations.

\section{Conclusion}

In this article, the development and operation of a regional digital archive system by a student team was discussed relative to PBL. The digital archive system must handle various types of historical records. As a result, the development of the system has become difficult and operation has become complicated. Thus, activities concerning the digital archives have become effective PBL.

As discussed in the previous section, students have a good command of software development tools and perform tasks using ticket driven development. However, requests to improve the system come constantly from the library; thus, the team lacks the time to prepare for takeover. In addition, the refactoring of source code and documentation are insufficient. How to manage tasks for system improvement and preparations for takeover must be addressed in future.

The benefits of our PBL are summarized in two points, reality and continuity.

First, we are dealing with a real-world problem. The system has been developed and operated by students in association with the client. The service provided by the system is used daily and nationwide. The students receive continuous feedback from the client and end users. This reality motivates students and makes students mature as we have shown.

Second, our activities continue over semesters and years by alternating generations of students. Thus, the activities covers most of the system's life cycle. This is effective for educating students about information systems comprehensively, and has an advantage over semester-wise PBL. The team consists of multi-year students so that annual turnover due to students graduating has less effect on team activities. As a result, various kinds of skills and culture are naturally transferred from seniors to newcomers. This is practical because this kind of team is normal in real-world projects.

An important achievement of our PBL is five years of continuous development and operation of a system providing a real-world service by a student team without critical problems. It has been suggested that the suite of activities of our PBL has the potential to be a methodology of practical PBL.

From a supervisor's perspective, we have realized the effectiveness of our activities as PBL sufficiently. However, to clarify and improve the educational effectiveness of our approach, we need to perform qualitative and quantitative analysis of various deliverables of the development and operation of the system. The deliverables include source code, issued 
tickets, technical documents, communication logs, etc.

\section{Acknowledgment}

The authors would like to thank the staff of Hakodate Central City Library for their support and assistance with this project.

\section{References}

[1] Z.J. Gackowski, "Case/Real-Life Problem-Based Learning with Information System Projects," Journal of Information Technology Education: Research, Vol. 2, 2003.

[2] K.H. Vat, "Teaching a Collaborative Model of IS Development through Problembased Learning," Information Systems Education Journal, Vol. 4, No. 102, 2006.

[3] Y. Tozawa, "The introduction of PBL in a Japanese graduate school university as an essential curriculum for Master Program of Information Systems Architecture," SEFI 36th Annual Conf., 2008.

[4] Hakodate City Central Library Digital Archives; http://archives.c.fun.ac.jp/ (accessed February 23, 2017).

[5] T. Deguchi, H. Nakahara, M. Takahashi, T. Okuno, and T. Kawashima, "Digital Archives CMS for Sharing Community Records and Civil Memories," IPSJ SIG Technical Report, Vol. 2012-DD-84, No. 4, 2012.

[6] CakePHP v3.2 - the rapid development php framework.; http://cakephp.org/ (accessed February 23, 2017).

[7] MongoDB for GIANT Ideas-MongoDB; https://www.mongodb.org/ (accessed February 23, 2017).

[8] Zoomify-Zoomable web images!; http://www.zoomify.com/ (accessed February 23, 2017).

[9] Overview - Redmine; http://www.redmine.org/ (accessed February 23, 2017).

[10] C. Bang, "What is Ticket Driven Development, and why is it attracting attention in Japan?," Dec. 2016; http://blogs.atlassian.com/2013/03/what-is-ticketdriven-development-and-why-is-it-attracting-attention-in-japan/ (accessed February 23, 2017).

[11] Daring Fireball: Markdown; http://daringfireball.net/projects/markdown/ (accessed February 23, 2017).

[12] Slack: Be less busy; https://slack.com/ (accessed February 23, 2017).

[13] T. Okuno, "Regional Vitalization Activities through PBL in Future University Hakodate," Proc. of the 4th Symp. of Transdisciplinery Federation of Science and Technology, 2012.

[14] A Guide to the Project Management Body of Knowledge (PMBOK Guide) Sixth Ed., Project Management Institute, 2013. 